\title{
Empirical Analysis on the Relationship between Tourism Development and Economic Growth in Sichuan
}

\author{
Li-hua $\mathrm{He}$ \\ School of Economics and Management, Sichuan Agricultural University \\ Ya'an 625014, China \\ Tel: 86-131-0835-3566_E-mail: helih1028@msn.cn \\ Xun-gang Zheng \\ School of Economics and Management, Sichuan Agricultural University \\ Ya'an 625014, China \\ Tel: 86-130-8630-5086Ｅ-mail: zxg9@163.com
}

\begin{abstract}
Sichuan has abundant tourist resources; the Government confirmed the tourism industry as the six pillar industries of the cross-century development in Sichuan. In recent years, the ratio of tourism to the province's GDP increased year by year. Based on stability test of the VAR model, this paper uses impulse response functions and variance decomposition method for econometric analysis, by using the economic data in 1990-2009 years. And the results indicated that, the development of tourism bases on economic growth, at the same time, economic growth is in need of tourism development.
\end{abstract}

Keywords: Tourism development, Economic growth, Empirical Study, VAR model

\section{Introduction}

Economic growth theory based on the aggregate production function is one of the major theories of Macro-economics. While only $2 / 3$ output is determinable by working time, while the other is determinable by leisure time (Kydland, 1995), and travel is based on leisure time. The impact of tourism on the developing of economic in present studies, considering the state of tourism industries in China, Wu (2003) proves that tourism plays a positive role in economic growth, by using quantitative analysis. According to empirical analysis, Liu and Hao(2009) approves that co-integration domestic tourism, international tourism and GDP are cointergrated. Based on empirical analysis on the relationship between tourism development and economic growth in Hainan, $\mathrm{Lu}$ (2005) thinks that tourism income is one of major factors of economics growth in Hainan. Based on the timing of the data 1985-2006, Deng and Lu use co-integration test, Granger causality test, Error correction model and impulse response function method to study tourism development and economic growth, and the results show that there is a long-term equilibrium relationship between them, the positive effect of tourism development on economic growth is much more significant in comparison with the negative effect. Zhang (2009) studies the influences of tourism development on the regional economic growth by the regressive model and Granger causality tests, and the empirical results show that they are mutually the condition as well as the cause and result. Cao (2006) thinks foreign exchange income from tourism has noticeable effect on economic growth. Tourism industry generates spillover effect by industrial correlation to promote economic growth.

Some domestic scholars have concerned about the relationship between tourism industry development and economic growth. Moreover, some of them study the relationship between modern tourism development and economic growth by normative analysis in Sichuan. However, there is lack of empirical study on the relation. Based on the current research, this paper makes an empirical study on the relationship between tourism development and economic growth by empirical analysis in Sichuan, by using Granger test, VAR model, impulse response function, and variance decomposition methods.

\section{The VAR models}

Using economic theory to describe the relation between the variables, couldn't offer the strict definition for dynamic relation between the variables frequently, besides endogenous variables may also appear on both sides of an equation, which make the estimation and inference complicated. Furthermore, nonstructural approach of 
multi-variable modeling is used to solve these problems. Moreover, the vector auto-regression model is one of the nonstructural approaches of multi-equation modeling.

A vector auto-regression (VAR) model is used in the prediction of the time series and dynamic influence on the variable of stochastic error. The model has been avoided modeling question for each endogenous variable is expressed as the function of the endogenous variable of lagging in the structural modeling method.

Given a set of time series variables $Y_{t}$, the basic VAR $(p)$ model is of the form

$$
Y_{t}=A_{1} Y_{t-1}+\ldots \ldots . A_{P} Y_{t-p}+B X_{t}+\varepsilon_{t}
$$

Where $Y_{t}$ is endogenous vector, $X_{t}$ is exogenous vector, $\mathrm{p}$ is number of lags, $A_{1}, A_{2} \ldots A_{p}, B$ are parameter matrix estimated, $\varepsilon_{t}$ is an unobservable zero-mean independent white noise, $\varepsilon_{t}$ series independent, whereas allows them dependent in the same period. In practice, it hope that lag $p$ is large enough to reflect dynamic characteristic of model, On the other hand, the longer lag length is, the more unknown coefficients are, the less degree of freedom is withal. Therefore, it is important to find a balance between lag length and degree of freedom. Lag length can be determined using either F-tests or information criteria, such as Akaike information criterion, Schwarz criterion.

$$
\begin{gathered}
A I C=-2 L / N+2 K / N \\
A I C=-2 L / N+2 \operatorname{Ln}(N) / N \\
L=-\frac{N}{2}(1+\operatorname{Ln}(2 \pi))-\frac{N}{2} \operatorname{Ln}\left(\frac{\sum_{t=1}^{N} \hat{e}_{t}^{2}}{N}\right)
\end{gathered}
$$

Where $\mathrm{k}$ is number of parameters estimated, $\mathrm{N}$ is number of useable observations.

\section{Empirical Analyses}

\subsection{Indexes and data}

Taking into account availability and reliability of data, this paper selects the gross domestic product (GDP) of Sichuan Province as indicators which measure the total of economic growth, uses total income of tourism as indicators which measure tourism development. Whereas social tranquility has great effect on tourism, the paper gets time series data from 1990 to 2009 of the two indicators by finishing material of Statistical Yearbook of Sichuan Province, and makes logarithmic transformation, denoted LnGDP and LnTour separately.

\subsection{Granger Causality}

To assert a causal relationship between TOUR and GDP, the relationship between lntour and lngdp could be analyzed by using Granger causality tests (Table 1).

According to Table 1, it can be seen that: 1) there is no Granger causality between GDP and TOUR when lag length is from one to five; 2) GDP Granger-causes TOUR at the 5\% significant level when lag length is from 2 six. Therefore, increasing as time the relationship between GDP and TOUR get obvious by degrees.

Economic analysis of two conclusions: 1) In Sichuan, the level of tourism development is not high, and the contribution of tourism to economic is not evident. During 1990 2009, there is greater development of Sichuan tourism development than ever. Tourism income has increased year by year, except in few special years (eg.2008). But, on the transverse comparison, the level of tourism development is also not high. Take international tourism that is one of the important indexes of tourism development as an example, for the first part of the year, foreign exchange income from tourism of Yunnan province is US\$ 491million, which surpasses the annual income from tourism of Sichuan province. Besides Sichuan economic development is one of the best among the western region in China, while the level of tourism development is not high, which shows that the positive impacts of economic growth on tourism development is not significant.

\subsection{Establish of Vector Auto-regression models}

\subsubsection{VAR Lag Order Selection}

The results provide VAR models of value of LR (sequential modified LR test statistic), FPE (Final prediction error), AIC (Akaike information criterion), SC (Schwarz information criterion) and HQ (Hannan-Quinn information criterion) from 0 to 4 steps in Table 2 and * indicates lag order selected by the criterion. Table 2 shows that criterion selects the lag order of VAR models is 2 . 
3.3.2 Establish of Vector Auto-regression models

$$
\left(\begin{array}{l}
\ln g d p_{t} \\
\ln \text { tour }_{t}
\end{array}\right)=\left(\begin{array}{ll}
1.5838 & 0.0229 \\
0.4134 & 0.8699
\end{array}\right)\left(\begin{array}{l}
\ln g d p_{t-1} \\
\ln \text { tour }_{t-1}
\end{array}\right)+\left(\begin{array}{cc}
-0.6804 & 0.0181 \\
0.3568 & -0.3246
\end{array}\right)\left(\begin{array}{l}
\ln g d p_{t-2} \\
\ln \text { our }_{t-2}
\end{array}\right)+\left(\begin{array}{c}
0.6324 \\
-3.7385
\end{array}\right)
$$

The order of the variable is Lntour and Lngdp in VAR model, where $\mathrm{AIC}=-2.9222, \mathrm{SC}=-2.6748$

According to equation (3), hysteresis coefficients of first-order lag term are positive, and it shows that both Lntour and Lngdp have positive effect on each other, and then viewed from coefficients, it could be concluded that first order lag variables have lager effect on themselves than effect on each other. Besides, according to hysteresis coefficients of second-order lag term, the positive influence among variables becomes much weaker.

\subsection{Stability Test}

Table 3 shows that no root lies outside the unit circle, and VAR satisfies the stability condition, Therefore, the VAR model is stability.

\subsection{Impulse Responses and Variance Decompositions}

\subsubsection{Impulse Responses}

As seen in Figure 1, the response of lntour to one S.D. innovations of itself is positive from the first period, which means tourism industry is accelerated significantly by itself. The response of lntour to one S.D. innovations of lngdp is positive and the response reach maximum when the period of response is 6 , then the response extent decrease. It means that economic growth accelerates tourism industry more significant in a long time.

From Figure 2, it can be seen that the response of lngdp to one S.D. innovations of lntour is positive from the first period, then the response reach maximum when the period of response is 5 , after that, the response extent decreases and keeps positive for a very long time. It means that tourism industry has positive effects on economic growth in the long term. The response of lngdp to one S.D. innovations of itself is positive from the first period. Moreover, the response reach maximum when the period of response is 4 , then the response extent decreases, which means that economic growth is accelerated significantly by itself in a short time, while economic growth may be caused by many numerous factors in the long term.

\subsubsection{Variance Decompositions}

It is defined as variance decomposition to separate the variation in an endogenous variable into the component shocks to the VAR for finding out information about the relative importance of each random innovation in affecting the variables in the VAR. Figure.3, Figure.4 are variance decomposition charts of lntour and lngdp.

As seen in Figure 3, the contribution to lntour is mainly from itself, while the contribution from lngdp increases gradually. It means that self-advancement of logistics industry is very significant, while the contribution from lngdp to lntour is quite important in long time.

As seen in Figure 4, the contribution from lntour to lngdp increases gradually, which means tourism industry will become much more important in economic growth in long time, while the contribution to lngdp from itself is relatively significant, then the contribution degree declines with period. It means that self-advancement of economic growth is very significant in the short term, whereas in the long term, economic growth needs other numerous factors in the long term.

\section{Conclusions and Recommendation}

In conclusion, the empirical study of tourism development and economic growth in Sichuan province has shown that: the role of tourism development in promoting economic growth is not obvious, while the role of economic growth in promoting development of tourism is great. However, as time goes on, the role of tourism development in promoting economic growth would be enhanced.

Furthermore, it can be seen that the main driving force of economic growth is from the secondary industry. The level of tourism development is lower in Sichuan province, and the role of promoting economic growth is not obvious. The history of economic development in developed countries shows that the rapid development of tourism will be in the medium-term period of industrialization. And with the development of information technology and economic globalization, the tourism industry will become an important part of the third industry as well as the whole national economy from economics of tourism. Besides, comparing with other provinces that tourism economy developed in West China, the contribution of tourism industry to economic growth is very important. From the analysis, it can be seen that it is important to enhance the level of development of the 
tourism industry and promote economic healthy and sustainable development in Sichuan province by creating actively conditions, while the main obstacle during the process of Sichuan's tourism development is the lack of master plan, developed respectively. At the present time, more attention is paid to tourism development by government. After Wenchuan Earthquake, government organizes some unified marketing plans, starts welfare public advertisement called Sichuan Retains Its Beauty in 2010, and Sichuan Travel Group was found to operational of tourism in July, 2010. While developing Sichuan's tourism needs further and practicable master plan, besides, it needs to increase fund input in infrastructures.

\section{References}

DENG Zutao, Lu yuqi. (2008). Empirical Analysis on the Relationship between Tourism Development and Economic Growth in Hubei. Statistics and Decision, 2008(17): 95-97.

FU Jingyan. (1999). Tourism Consumption and Economic Growth. Tourism Science, 1999(3):18-22.

JAMES H. Stock, Mark W. Watson. (2007). Introduction to Econometrics (Second Edition), Shanghai People's Publishing House, 04, pp.639-641.

KIM, Chen, \& Jang. H.J. Kim, M.H. Chen and S.C. Jang. (2006). Tourism expansion and economic development: The case of Taiwan, Tourism Management, 27 (5) (2006):925-933.

LI Xinchun. (2007). China Management Studies. Economic Science Press, 2 (3):73.

LIU Yinghui, Hao suo. (2009). Comparative Study on Domestic and International Tourism to Promote Economic Growth. Statistics and Decision, (14):120-123.

SHAO Wei, Cheng yuzhong. (2006). On the Dual-track Phenomenon of Foreign Holiday-making Travel and Its Enlightenment to China. Tourism Tribune, (3):93-96.

WEI Xiang. (2005). Leisure Time and Economic Growth:--Evidence from the Chinese Data. Journal of Finance and Economic, 31(10):98-107.

XIE Yanjun. (1999). Tourism. Beijing: China Travel \& Tourism Press. 225-227.

YANG Quanxin. (2001). Analysis on Sichuan tourism. Business World, 2001(4):20-24.

YANG Yong. (2006). Empirical Analysis on the Relationship between Tourism and Economic Growth in China. Tourism Science, 20(2):40-46.

YI Danhui. (2008). Data Analysis and Application Eviews. Beijing: China Renmin University Press, 207-234.

ZHANG Airu. (2009). The Effects of Development Qinghai Tourism on Regional Economic Growth. Statistics and Decision, (15):97-98.

Table 1. Granger Causality Tests

\begin{tabular}{|c|c|c|c|c|}
\hline Null Hypothesis: & lag & F-Statistic & Probability & Conclusion \\
\hline \multirow{12}{*}{$\begin{array}{l}\text { LnTOUR does not Granger Cause LnGDP } \\
\text { LnGDP does not Granger Cause LnTOUR }\end{array}$} & \multirow{2}{*}{1} & 0.95818 & 0.3422 & Accept \\
\hline & & 0.02323 & 0.8808 & Accept \\
\hline & \multirow{2}{*}{2} & 0.85892 & 0.4463 & Accept \\
\hline & & 0.12449 & 0.8839 & Accept \\
\hline & \multirow{2}{*}{3} & 0.75747 & 0.5430 & Accept \\
\hline & & 0.02212 & 0.9952 & Accept \\
\hline & \multirow{2}{*}{4} & 0.4919 & 0.7429 & Accept \\
\hline & & 0.30343 & 0.8669 & Accept \\
\hline & \multirow{2}{*}{5} & 2.40166 & 0.2082 & Accept \\
\hline & & 0.693 & 0.6566 & Accept \\
\hline & \multirow{2}{*}{6} & 29.161 & 0.1408 & Accept \\
\hline & & 2583.29 & $0.0151 * *$ & Reject \\
\hline
\end{tabular}

Notes: sign “***”, “**”, “*”, indicates significance under 1\%, 5\%, 10\%of the levels respectively. 
Table 2. VAR Lag Order Selection Criteria

\begin{tabular}{|c|c|c|c|c|c|c|}
\hline Lag & LogL & LR & FPE & AIC & SC & HQ \\
\hline 0 & -10.2763 & NA & 0.0159 & 1.5345 & 1.6311 & 1.5395 \\
\hline 1 & 31.4757 & 67.8469 & 0.0001 & -3.1845 & -2.8947 & -3.1696 \\
\hline 2 & 38.9351 & $10.2567^{*}$ & $0.0000^{*}$ & $-3.6169^{*}$ & $-3.1340^{*}$ & $-3.5922^{*}$ \\
\hline 3 & 40.4749 & 1.7323 & 0.0001 & -3.3094 & -2.6334 & -3.2747 \\
\hline 4 & 43.6733 & 2.7986 & 0.0002 & -3.2092 & -2.3400 & -3.1647 \\
\hline
\end{tabular}

Table 3. Stability Condition Check

\begin{tabular}{|c|c|}
\hline Root & Modulus \\
\hline 0.9409 & 0.9409 \\
\hline $0.489995-0.433129 \mathrm{i}$ & 0.6540 \\
\hline $0.489995+0.433129 \mathrm{i}$ & 0.6540 \\
\hline 0.5328 & 0.5328 \\
\hline
\end{tabular}

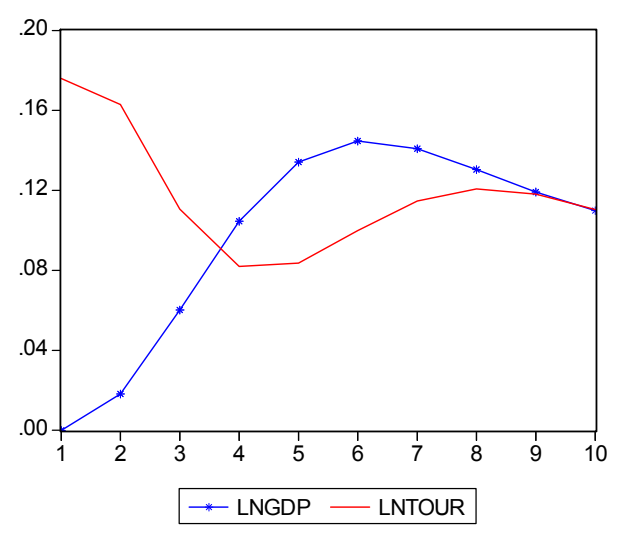

Figure 1. Response of LNTOUR to Cholesky One S.D. Innovations

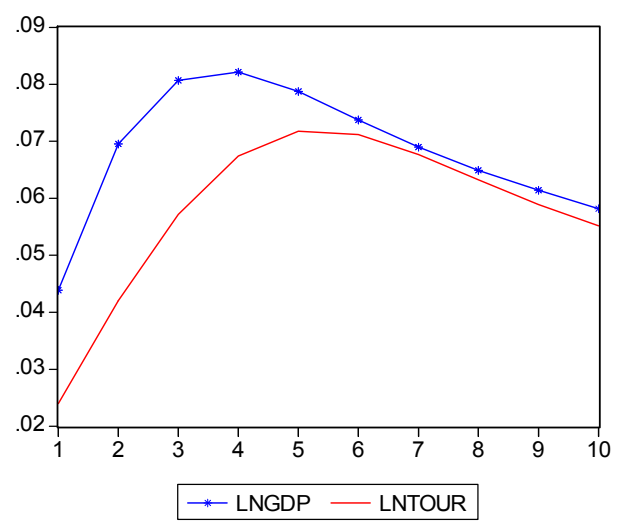

Figure 2. Response of LNGDP to Cholesky One S.D. Innovations 


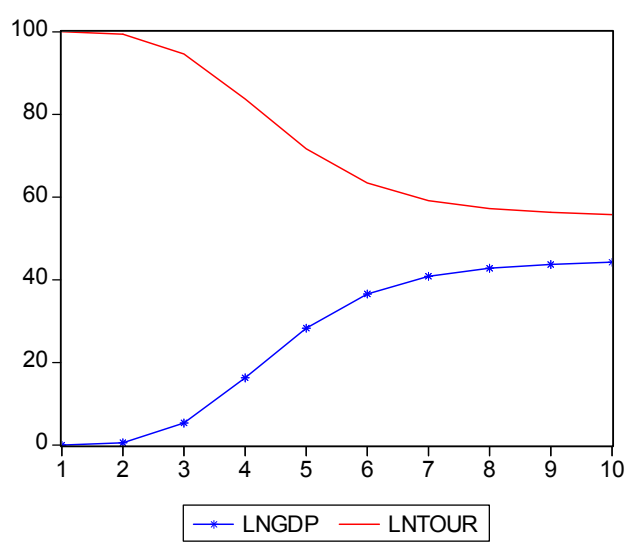

Figure 3. Variance Decomposition of LNTOUR

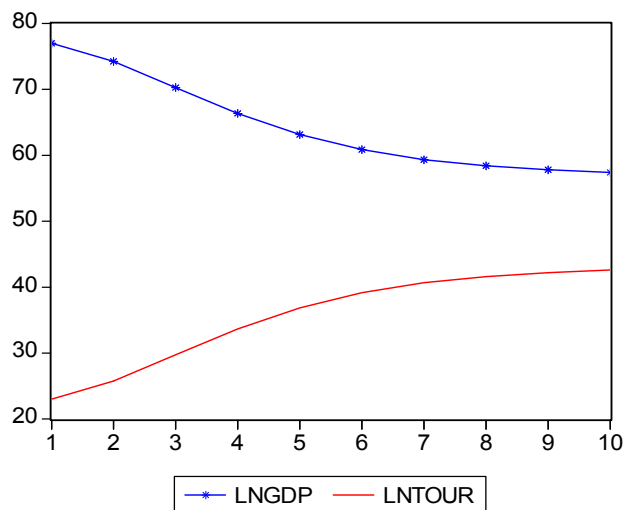

Figure 4. Variance Decomposition of LNGDP 